\title{
Test Device of Soil Outline and Compactness Distribution on Seedbed Based on Sensors
}

\author{
Caiyun $\mathrm{Lu}^{1,2}$, Liwei $\mathrm{Li}^{2}{ }^{2}$ Zhijun Meng ${ }^{2}$, Xiu Wang ${ }^{2(\bowtie)}$, and Qingjie Wang ${ }^{1}$ \\ ${ }^{1}$ College of Engineering, China Agricultural University, Beijing 100083, China \\ \{lucaiyun,wangqingjie\}@cau.edu.cn \\ ${ }^{2}$ Beijing Research Center of Intelligent Equipment for Agriculture, Beijing 100097, China \\ $\{$ lilw, mengzj, wangx\}@nercita.org.cn
}

\begin{abstract}
To measure soil compactness distribution on seedbed, a new test device of soil outline and compactness distribution on seedbed based on sensors was designed. The paper elaborated working principle and structure of the device and its working parameters were determined. Calibration experiments obtained linear equation between $\mathrm{L}$ and $\mathrm{I}$ for distance sensor and linear equation between $\mathrm{m}$ and $\mathrm{I}$ and linear equation between $\mathrm{F}$ and $\mathrm{I}$ for each pressure sensor Field experiment showed that designed device could test soil outline and soil compactness at the same time.
\end{abstract}

Keywords: Soil compactness distribution, soil outline, test device, sensor.

\section{Introduction}

Soil compactness, especially on the seedbed, is one of the most important factors to affect soil and crop performance, such as crop emergency, soil and moisture resistance, and improvement of enzyme activity in soil. In addition, soil compactness can adjust soil nutrition, moisture, temperature, air and the physical, biology and chemical process, and then affect the capacity of crop nutrition absorption and growth of root, leaf and other organs [1 3]. Suitable soil compactness makes soil layers compactness, and keeps seed in touch with soil, which promotes germinating and root system growing; at the same time, compactness soil reduces soil porosity, water in deeper soil layers evaporation and erosion, which improves soil moisture conservation. Thus, suitable soil packing after seeding is usually made for soft soil to increase soil compactness, which satisfies the requirement of crop growth [4 6]. However, excessive soil compactness on seedbed will result in soil porosity too low, and reduce soil permeability, saturated hydraulic conductivity, and then reduce water and nutrition absorption for crop [7 9]; besides, excessive soil compactness leads to area reduction between minerals and water, and root growth resistance increases as soil compactness increasing, and affects crop yield. For cross-section of seedbed, the differences of soil compactness distribution are an important factor to impact water adsorption of seed and root growth [10]. The largest soil compactness occurs in the middle, which makes soil layers compactness, and keeps seed in touch with soil [11]. It is beneficial to water absorption and root growth, and water evaporation and erosion reduction [12]. Soil compactness in the sides is lower than that in the middle, which ensures soil moisture permeability, breathability and use efficiency of water and fertilizer. Soil compactness distribution is significantly affected by soil outline, so research of soil compactness distribution combination with soil outline is significative. 
At present, soil compactness test device used for measuring soil compactness distribution is rare, especially together with soil outline measuring. Therefore, a new test device of soil outline and compactness distribution in the filed based on sensors is designed, and its performance was tested.

\section{Structure and Working Principle}

\subsection{Structure}

Structure of test device of soil outline and compactness distribution in the filed based on sensors is shown in Fig. 1a. The device is mainly composed of frame, test component of soil outline, test component of soil compactness distribution, control box and storage battery. Test component of soil outline and test component of soil compactness distribution are the key components. The dimension of the device is shown in Table 1.

Table 1. Dimension of test device

\begin{tabular}{ll}
\hline Length & $118 \mathrm{~cm}$ \\
\hline Width & $83 \mathrm{~cm}$ \\
Height & $70 \mathrm{~cm}$ \\
\hline
\end{tabular}

Test component of soil compactness distribution is mainly composed of motor 1 , coupler 1, screw pair 1 with screw 1, slider 1 and guide rail 1, 25 test units with pressure sensor and test pin, angle iron; test units was fixed on slider 1 (Fig.1b).

Test component of soil outline is mainly composed of motor 2, coupler 2, screw pair 2 with screw 2 and slider 2, guide rail 2 and distance sensor; distance sensor is fixed on slider 2 (Fig 1c).

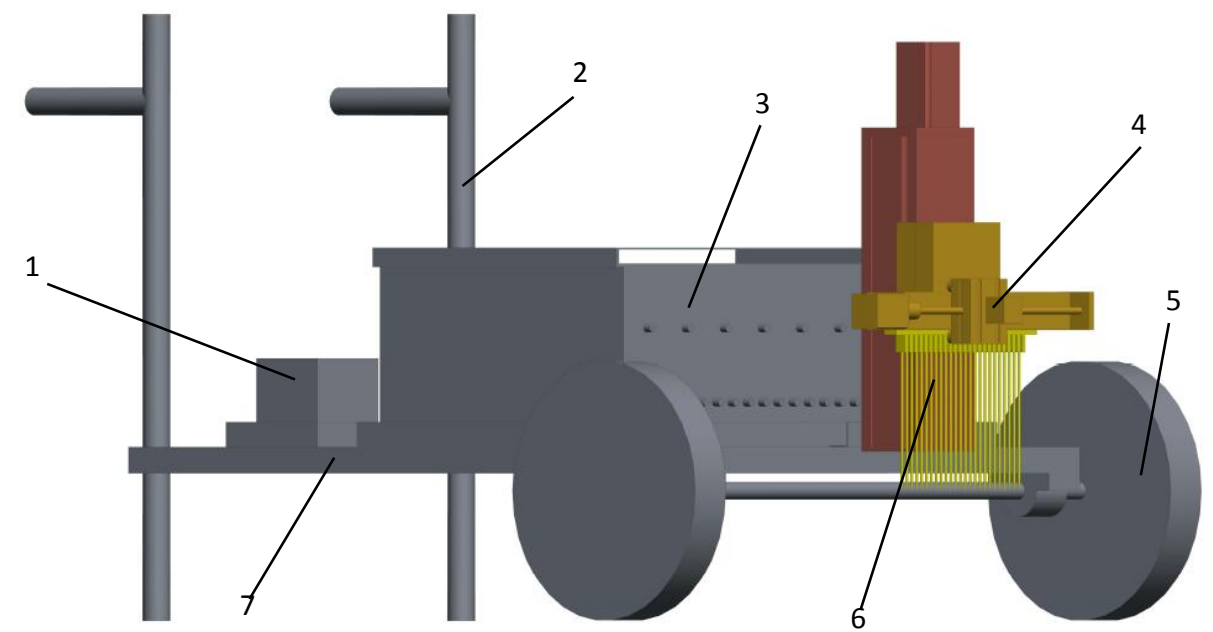

1. Storage battery 2. Armrest 3. Control box 4 . Test component of soil outline 5. Wheel 6. Test component of soil compactness distribution 7. Frame (a) Test device of soil outline and compactness distribution in the field 


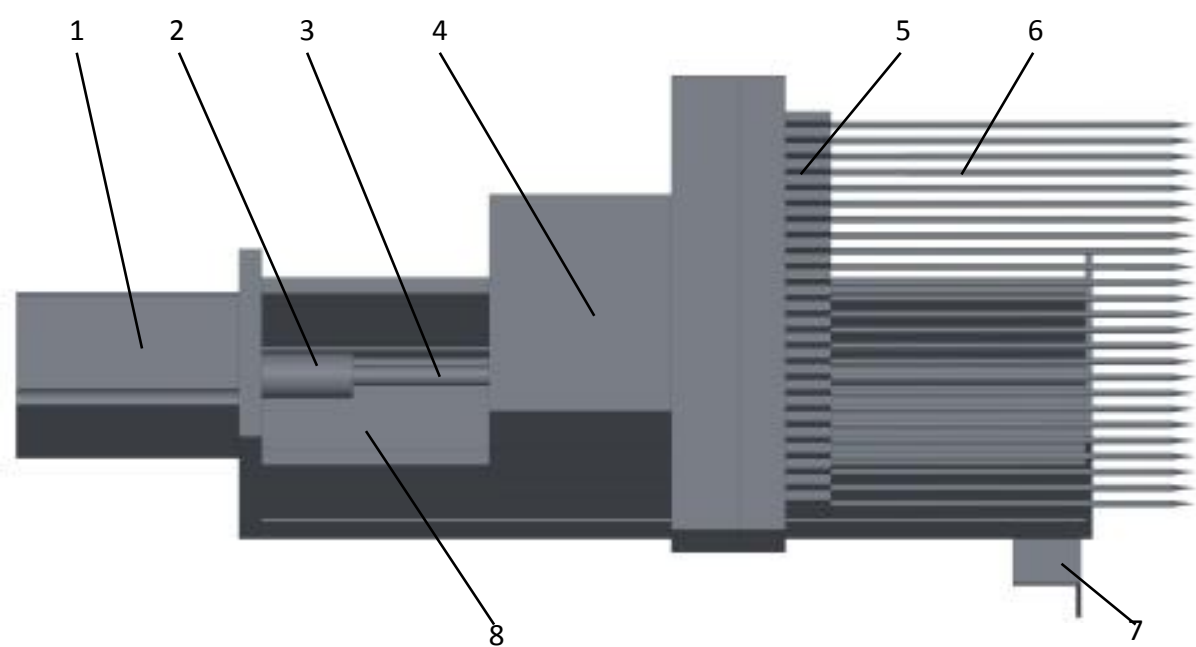

1. Motor1 2. Coupler 1 3. Screw 1 4. Slider 1 5. Pressure sensor 6. Test pin 7. angle iron 8 . Guide rail 1

(b) Test component of soil compactness distribution

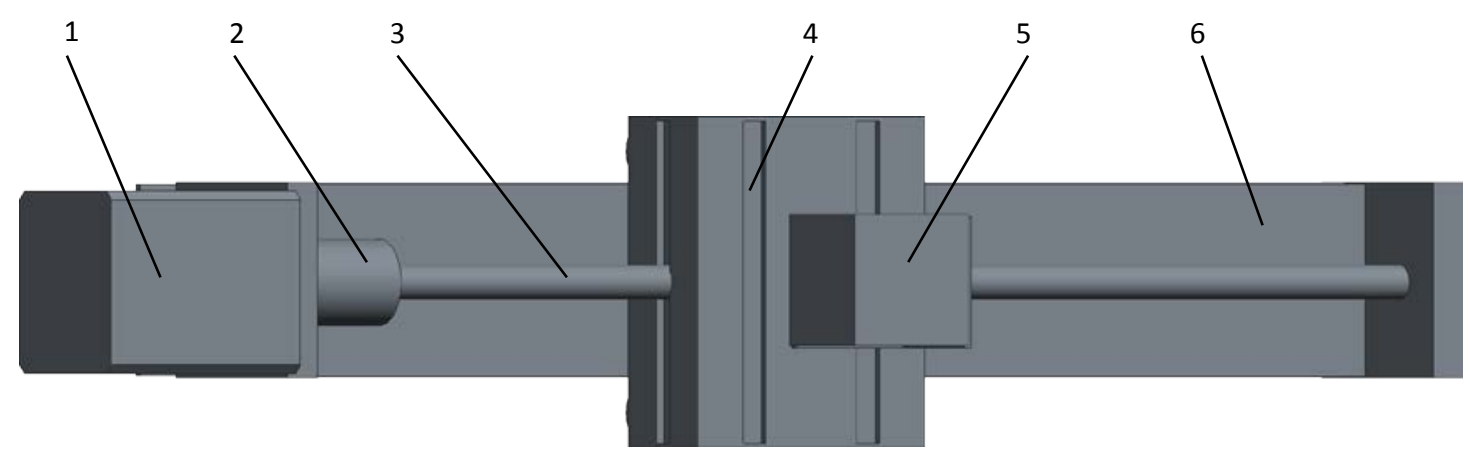

1. Motor 2 2. Coupler 2 3. Screw 2 4. Slider 2 5. Distance sensor 6 . Guide rail 2

(c) Test component of soil outline

Fig. 1. Test device of soil outline and compactness distribution in the field

\section{$2.2 \quad$ Working principle}

Test component of soil compactness distribution is fixed in front of frame by angle iron, and moves up and down by screw pair 1 . Test component of soil outline is fixed on slider 1, and moves up and down together with slider 1; at the same time, distance sensor moves in horizontal to fro by screw pair 2. Control box and storage battery are installed on the frame behind test component of soil compactness distribution, and support power and instructions for the device. Armrest and wheel are separately installed on the frame to move the device to designed position.

\subsubsection{Working principle of test component for soil outline}

During test, test component for soil outline is perpendicular to furrow by opener and positioned on the furrow (Fig. 2). Adjust distance sensor to the rim of furrow cross section, and get the distance $\left(\mathrm{L}_{1}\right)$ between test point to distance sensor, and then move distance sensor a fixed distance along screw, and test the distance $\left(\mathrm{L}_{2}\right)$ between second point and distance sensor and then move distance sensor the fixed distance. Repeat above steps until getting the distance $\left(\mathrm{L}_{\mathrm{n}}\right)$ between the point on another rim and distance sensor. Take the minimum distance from the tested distance as criterion (L). And the ground for this point is called reference level. Separately get the difference value between tested distance $\left(\mathrm{L}_{1}, \mathrm{~L}_{2}, \ldots \mathrm{L}_{\mathrm{n}}\right)$ and $\mathrm{L}$, and then draw the outline of seedbed based on criterion (L). 


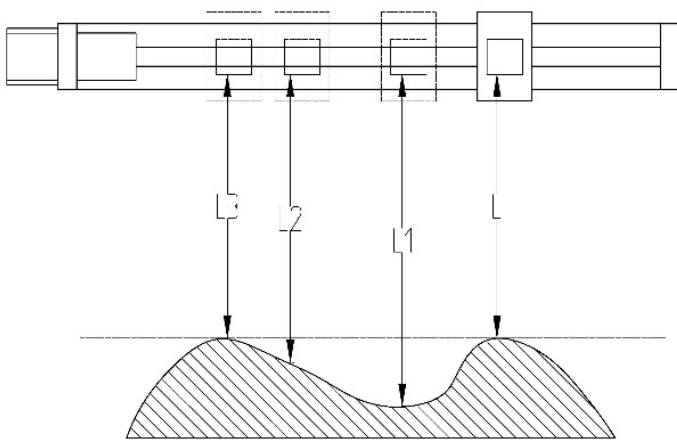

Fig. 2. Test device of soil outline and compactness distribution in the field

\subsubsection{Working principle of test component for soil compactness distribution}

Soil compactness distribution is tested by static inserting method. After soil outline test finished, the distance $(\mathrm{H})$ between test pin and reference level is calculated and test component for soil compactness distribution is moved down to make the pin touch the soil. Insert test pin into the soil in a constant and slow speed by motor 1 . In the process, each pressure sensor gets one pressure force and gets the soil compactness by the following formula:

$$
P=F / S
$$

Where $P$ is soil compactness; $F$ is pressure force; $S$ is the area of the bottom of the pin.

The device can complete 25 soil compactness once, and get the soil compactness distribution on seedbed.

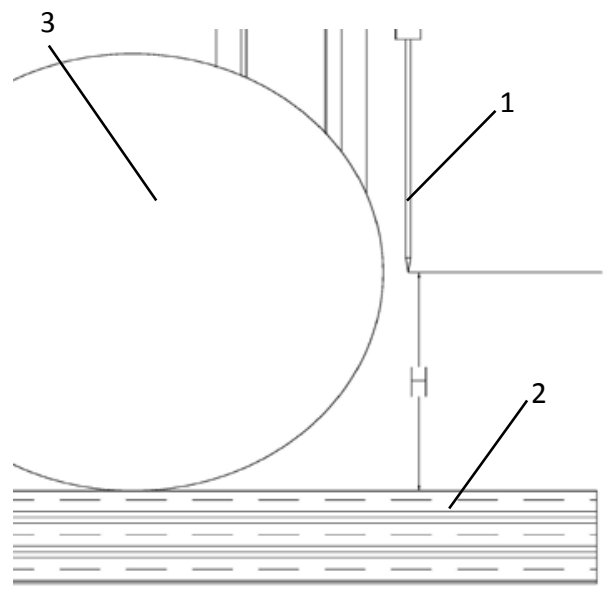

Fig. 3. The initial position of the test pin

\section{Design of key components}

\subsection{Test component for soil outline}

\subsubsection{Parameter of distance sensor}

Outline test of object surface includes contact and non-contact test according to test methods. To soil, contact test is apt to damage soil outline, and result in inaccuracy. Therefore, non-contact distance sensor is used to test soil outline.

At present, distance sensor includes ultrasonic, infrared and laser sensors, etc. Ultrasonic sensor tests distance by ultrasonic emission. Test precision is $\mathrm{cm}$ degree, 
but ultrasonic is apt to disturb by barrier. Infrared sensors tests distance by infrared signals. According to the signal intensity, the distance is calculated out; however, infrared sensor is easy to disturbed by light [13-14]. Laser sensor gets distance by time differences between laser sending and receiving [15-16]. Test precision is up to $\mathrm{mm}$ degree, and is not disturbed by light and barrier. Therefore, laser sensor is used to detect distance in the research.

FT50 RLA-220-S1L8 sensor made in Germany is selected (Fig. 4). The sensor has a rapid response, and strong ability to avoid light disturbance, it is suitable for all surface detecting [17]. Table 1 shows the key parameters of the sensor.

Table.2. Parameters of range sensor

\begin{tabular}{cc}
\hline Power voltage & $24 \mathrm{VDC}$ \\
\hline Test range & $80 \mathrm{~mm} \sim 300 \mathrm{~mm}$ \\
Resolution & $0.08 \sim 0.3 \mathrm{~mm}$ \\
Response time & $<0.5 \mathrm{~ms}$ \\
Output current & $4 \sim 20 \mathrm{~mA}$ \\
Linearity & $<0.25 \%$ \\
Working power & $18-30 \mathrm{~V}$ DC \\
Linkage type & $\mathrm{M} 128 \mathrm{pins}$ \\
Spot size & $2 \mathrm{~mm} \times 4 \mathrm{~mm}$ \\
Dimension & $50 \times 50 \times 17 \mathrm{~mm}$ \\
\hline
\end{tabular}

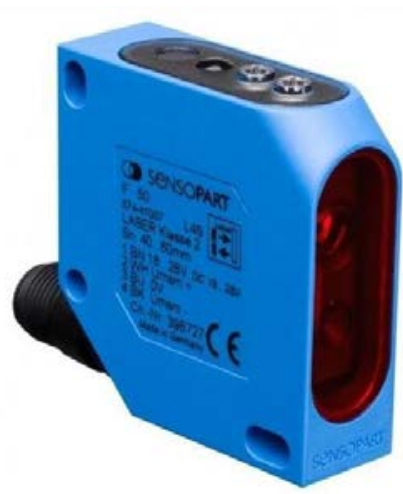

Fig. 4. Range sensor

\subsubsection{Parameters of screw pair 2}

Screw pair 2 is composed of guide rail 2, screw 2, slider 2 and motor 2 etc. It is used to drive distance sensor moving in a designed speed along the horizontal direction on guide rail 2. The distance between two tested points is fixed when interval between two tests is fixed, thus distance for different test points from soil surface to distance sensor is got.

Key parameters of screw pair 2 include speed of slider 2 (horizontal speed of distance sensor), moving precision and effective movement etc.

(1) Speed and moving precision

The width of furrow by openers is usually less than $100 \mathrm{~mm}$. To ensure the accuracy of soil outline, distance of adjacent tested points should be as small as possible. Therefore, speed of screw pair 2 used in the study can be adjusted among $1 \sim 66 \mathrm{~mm} / \mathrm{s}$. Considered than interval between adjacent tested points for soil compactness is $8 \mathrm{~mm}$ (see 2.2), speed of screw pair 2 is selected as proxy of $8 \mathrm{~mm}(1 \mathrm{~mm}, 2 \mathrm{~mm}, 4 \mathrm{~mm}$ and $8 \mathrm{~mm})$. The moving precision is $0.1 \mathrm{~mm}$.

(2) Effective movement

To ensure soil outline of entire furrow could be obtained, the effective movement of slider 2 must be greater than $100 \mathrm{~mm}$; effective movement of slider 2 in the study selects $240 \mathrm{~mm}$.

(3) Selection of motor 2

Motor 2 is used to drive screw 2 rotating and slider 2 moving on the guide rail 2. According to the requirements, 42 series two-phase stepping motor is used, and load 


\subsection{Test component for soil compactness distribution}

Test component for soil compactness distribution is composed of screw pair 1 and 25 units for testing soil compactness.

\subsubsection{Test width}

To ensure soil compactness of entire furrow could be obtained, test width must be greater than $100 \mathrm{~mm}$; test width in the study selects $200 \mathrm{~mm}$ with 25 test units and interval between adjacent units $8 \mathrm{~mm}$.

\subsubsection{Parameters of screw pair 1}

Screw pair 1 is composed of guide rail 1 , screw 1 , slider 1 and motor 1 etc. It is used to drive test units moving in a designed speed along the vertical direction on guide rail 1 and insert test pins into soil to a designed depth.

Key parameters of screw pair 1 include speed of slider 1 (speed of test units), moving precision and effective movement etc.

(1) Speed and moving precision

In this study, speed of screw pair 1 used can be adjusted among $1 \sim 66 \mathrm{~mm} / \mathrm{s}$. The moving precision is $0.1 \mathrm{~mm}$.

(2) Effective movement

Seeding depth is usually $30 \sim 50 \mathrm{~mm}$, and fertilizing depth $80 \sim 100 \mathrm{~mm}$, therefore furrow depth by openers less than $100 \mathrm{~mm}$. To ensure soil compactness for entire furrow tested, effective movement is designed as $160 \mathrm{~mm}$.

(3) Selection of motor 1

Motor 1 is used to drive screw 1 rotating and slider 1 moving on the guide rail 1 and test pins inserting into soil. Considered that load increasing as soil depth increasing, 57 series two-phase stepping motor is used, and load range $\leq 40 \mathrm{~kg}$.

\subsubsection{Pressure sensor}

One test unit is composed of one pressure and one test pin.

Pressure sensor is used to obtain the force of test pin inserting soil. Mini pressure sensor EVT-10G-5kg (Fig. 5) is used in this study due to limited space. The parameters of the sensor are shown in Table 3.

Table.3. Parameters of each pressure sensor

\begin{tabular}{cc}
\hline Power voltage & $24 \mathrm{VDC}$ \\
\hline Test range & $0 \sim 5 \mathrm{~kg}$ \\
\hline Precision & $50 \mathrm{~g}$ \\
Working temperature & $-20 \sim 60^{\circ} \mathrm{C}$ \\
Safe over range & $150 \% \mathrm{~F} . \mathrm{S}$ \\
Zero output & $\pm 1 \% \mathrm{~F} . \mathrm{S}$ \\
Output current & $4 \sim 20 \mathrm{~mA}$ \\
\hline
\end{tabular}

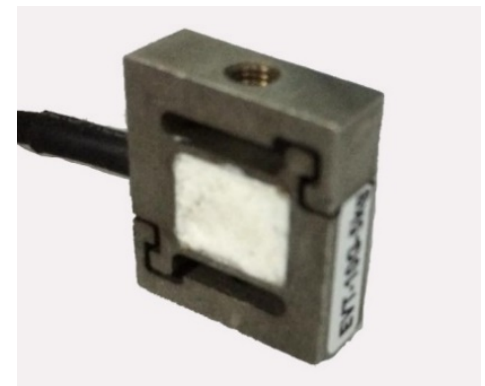

Fig. 5. Pressure sensor 
Test pin is installed at the bottom of pressure sensor. According to Criterion by ASABE, the taper angle is designed $30^{\circ}$, the max diameter is $2.5 \mathrm{~mm}$, and the base area is $4.9 \times 10-6 \mathrm{~m} 2[18-19]$.

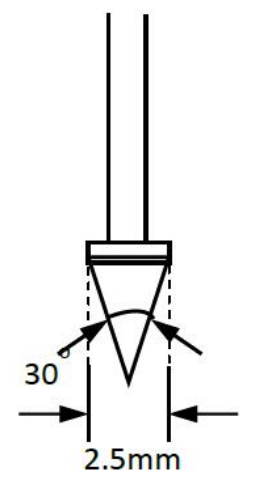

\subsection{Control box}

Fig. 6. Dimension of test pin

Control box is composed of PLC controller, stepper motor drivers, and A/D converter. The function includes controlling motors working and receiving data.

\section{$4 \quad$ Field experiment and result analysis}

\subsection{Material and methods}

To verify the accuracy and practicability of the device, calibration of sensors and field experiment was conducted near Beijing, China, in an area with a temperate continental climate and four distinct seasons.

(1) Calibration of distance sensor

Before working, distance sensor was calibrated to compensate with zero drift. Hardboard and vernier caliper were used to calibrate sensors. Set the distance between hardboard and distance sensor L. The formula between $\mathrm{L}$ and output current I was as following:

$$
L=b+k^{*} I
$$

Put hardboard in different distance with distance sensor measured by vernier caliper, and measure output current In, residual error of test point $i$ between calibration data and response value on the fitting straight-line was the following formula:

$$
\begin{gathered}
\Delta_{i}=L_{i}-\left(k^{*} I_{i}+b\right) \\
\sum_{i=1}^{n} \Delta_{i}^{2}=\sum_{i=1}^{n}\left[L_{i}-\left(k^{*} I_{i}+b\right)\right]^{2}
\end{gathered}
$$

Derivation of $\mathrm{k}$ and $\mathrm{b}$ with least square method was shown in the following:

$$
\begin{aligned}
& \frac{\partial}{\partial k} \sum_{i=1}^{n} \Delta_{i}^{2}=2 \sum_{i=1}^{n}\left[L_{i}-\left(k^{*} I_{i}+b\right)\right]\left(-I_{i}\right)=0 \\
& \frac{\partial}{\partial b} \sum_{i=1}^{n} \Delta_{i}^{2}=2 \sum_{i=1}^{n}\left[L_{i}-\left(k^{*} I_{i}+b\right)\right](-1)=0
\end{aligned}
$$

Formula of $\mathrm{k}$ and $\mathrm{b}$ were obtained from (5) and (6):

$$
\begin{aligned}
& k=\frac{n \sum_{i=1}^{n} I_{i} L_{i}-\sum_{i=1}^{n} I_{i} \sum_{i=1}^{n} L_{i}}{n \sum_{i=1}^{n} I_{i}^{2}-\left(\sum_{i=1}^{n} I_{i}\right)^{2}} \\
& b=\frac{\sum_{i=1}^{n} I_{i}^{2} \sum_{i=1}^{n} L_{i}-\sum_{i=1}^{n} I_{i} \sum_{i=1}^{n} I_{i} L_{i}}{n \sum_{i=1}^{n} I_{i}^{2}-\left(\sum_{i=1}^{n} I_{i}\right)^{2}}
\end{aligned}
$$

Linear equation between L and I were obtained from formula (2), (7) and (8). 
(2) Calibration of pressure sensors

Before working, pressure sensors were calibrated to compensate with zero drift. Weights were used to calibrate sensors. The formula between mass $m$ and output current $I$ was as following:

$$
m=b+k * I
$$

Put weights with different mass on pressure sensor, and measure output current $I_{n}$, residual error of test point $i$ between calibration data and response value on the fitting straight-line was the following formula:

$$
\begin{aligned}
\Delta_{i} & =m_{i}-\left(k * I_{i}+b\right) \\
\sum_{i=1}^{n} \Delta_{i}^{2} & =\sum_{i=1}^{n}\left[m_{i}-\left(k * I_{i}+b\right)\right]^{2}
\end{aligned}
$$

Derivation of $k$ and $b$ with least square method was shown in the following:

$$
\begin{aligned}
& \frac{\partial}{\partial k} \sum_{i=1}^{n} \Delta_{i}^{2}=2 \sum_{i=1}^{n}\left[m_{i}-\left(k * I_{i}+b\right)\right]\left(-I_{i}\right)=0 \\
& \frac{\partial}{\partial b} \sum_{i=1}^{n} \Delta_{i}^{2}=2 \sum_{i=1}^{n}\left[m_{i}-\left(k * I_{i}+b\right)\right](-1)=0
\end{aligned}
$$

Formula of $k$ and $b$ were obtained from (12) and (13):

$$
\begin{aligned}
& k=\frac{n \sum_{i=1}^{n} I_{i} m_{i}-\sum_{i=1}^{n} I_{i} \sum_{i=1}^{n} m_{i}}{n \sum_{i=1}^{n} I_{i}^{2}-\left(\sum_{i=1}^{n} I_{i}\right)^{2}} \\
& b=\frac{\sum_{i=1}^{n} I_{i}^{2} \sum_{i=1}^{n} m_{i}-\sum_{i=1}^{n} I_{i} \sum_{i=1}^{n} I_{i} m_{i}}{n \sum_{i=1}^{n} I_{i}^{2}-\left(\sum_{i=1}^{n} I_{i}\right)^{2}}
\end{aligned}
$$

Linear equation between $m$ and $I$ were obtained from formula (9), (14) and (15); and linear equation between $F$ and $I$ were obtained from $F=m^{*} g$.

(3) Field experiment

Field experiment was conducted on soil after wheat seeding. Soil outline and soil compactness of seedbed were tested to verify the practicability of the device.

\subsection{Result analysis}

(1) Calibration of distance sensor

The relation between $L$ and $I$ was shown in Fig.7. Linear equation between $L$ and $I$ can be expressed by the following:

$$
\begin{gathered}
L=13.752 * I+25.025 \\
R^{2}=1
\end{gathered}
$$

The result showed that relation between $\mathrm{L}$ and I had good linearity ( $\mathrm{R} 2=1)$, measure range of distance sensor was $40 \mathrm{~mm} \sim 300 \mathrm{~mm}$, and relative error was less than $0.25 \%$.

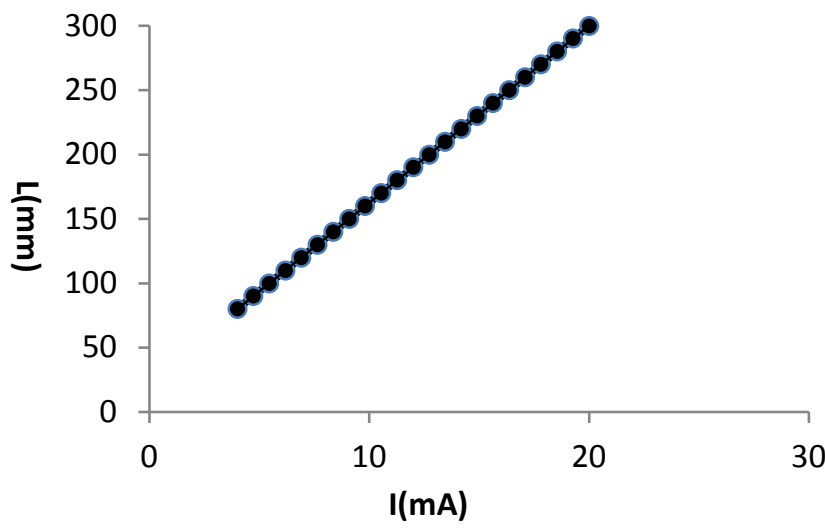

Fig. 7. Relation between distance (L) and current (I)

(2) Calibration of pressure sensors 
Table 4 showed the linear equation between $m$ and $I$ and linear equation between $F$ and $I$ for each pressure sensor. Results showed that measure range of pressure sensor was $50 \mathrm{~g} \sim 5 \mathrm{~kg}$, relative error was less than $5 \%$, and R2 was close to 1 , and had good linearity.

Table.4. Linear fitting equation of each pressure sensor

\begin{tabular}{|c|c|c|c|}
\hline Sensor NO. & Linear equation between $\mathrm{m}$ and $\mathrm{I}$ & Linear equation between $\mathrm{F}$ and $\mathrm{I}$ & $\mathrm{R}^{2}$ \\
\hline 1 & $\mathrm{~m}=0.3126 * \mathrm{I}-1.2132$ & $\mathrm{~F}=3.126 * \mathrm{I}-12.132$ & 1 \\
\hline 2 & $\mathrm{~m}=0.3427 * \mathrm{I}-1.2892$ & $\mathrm{~F}=3.427 * \mathrm{I}-12.892$ & 0.99 \\
\hline 3 & $\mathrm{~m}=0.3135 * \mathrm{I}-1.2406$ & $\mathrm{~F}=3.135 * \mathrm{I}-12.406$ & 1 \\
\hline 4 & $\mathrm{~m}=0.3135 * \mathrm{I}-1.2841$ & $\mathrm{~F}=3.135 * \mathrm{I}-12.841$ & 1 \\
\hline 5 & $\mathrm{~m}=0.3126 * \mathrm{I}-1.2315$ & $\mathrm{~F}=3.126 * \mathrm{I}-12.315$ & 1 \\
\hline 6 & $\mathrm{~m}=0.3139 * \mathrm{I}-1.2564$ & $\mathrm{~F}=3.139 * \mathrm{I}-12.564$ & 1 \\
\hline 7 & $\mathrm{~m}=0.3133 * \mathrm{I}-1.2843$ & $\mathrm{~F}=3.133 * \mathrm{I}-12.843$ & 1 \\
\hline 8 & $\mathrm{~m}=0.3111 * \mathrm{I}-1.196$ & $\mathrm{~F}=3.111 * \mathrm{I}-11.96$ & 0.99 \\
\hline 9 & $\mathrm{~m}=0.3141 * \mathrm{I}-1.2687$ & $\mathrm{~F}=3.141 * \mathrm{I}-12.687$ & 1 \\
\hline 10 & $\mathrm{~m}=0.3129 * \mathrm{I}-1.2856$ & $\mathrm{~F}=3.129 * \mathrm{I}-12.856$ & 1 \\
\hline 11 & $\mathrm{~m}=0.3137 * \mathrm{I}-1.1927$ & $\mathrm{~F}=3.137 * \mathrm{I}-11.927$ & 1 \\
\hline 12 & $m=0.3143 * I-1.2315$ & $\mathrm{~F}=3.143 * \mathrm{I}-12.315$ & 1 \\
\hline 13 & $\mathrm{~m}=0.3125 * \mathrm{I}-1.224$ & $\mathrm{~F}=3.125 * \mathrm{I}-12.24$ & 1 \\
\hline 14 & $\mathrm{~m}=0.3138 * \mathrm{I}-1.2612$ & $F=3.138 * I-12.612$ & 1 \\
\hline 15 & $\mathrm{~m}=0.3136 * \mathrm{I}-1.2646$ & $F=3.136 * I-12.646$ & 1 \\
\hline 16 & $\mathrm{~m}=0.3154 * \mathrm{I}-1.0771$ & $\mathrm{~F}=3.154 * \mathrm{I}-10.771$ & 1 \\
\hline 17 & $\mathrm{~m}=0.3113 * \mathrm{I}-1.1517$ & $\mathrm{~F}=3.113 * \mathrm{I}-11.517$ & 1 \\
\hline 18 & $\mathrm{~m}=0.3152 * \mathrm{I}-1.2477$ & $\mathrm{~F}=3.152 * \mathrm{I}-12.477$ & 1 \\
\hline 19 & $\mathrm{~m}=0.309 * \mathrm{I}-1.2277$ & $\mathrm{~F}=3.09 * \mathrm{I}-12.277$ & 1 \\
\hline 20 & $\mathrm{~m}=0.3149 * \mathrm{I}-1.2624$ & $\mathrm{~F}=3.149 * \mathrm{I}-12.624$ & 1 \\
\hline 21 & $\mathrm{~m}=0.3171 * \mathrm{I}-1.2629$ & $\mathrm{~F}=3.171 * \mathrm{I}-12.629$ & 1 \\
\hline 22 & $\mathrm{~m}=0.3142 * \mathrm{I}-1.3375$ & $\mathrm{~F}=3.142 * \mathrm{I}-13.375$ & 1 \\
\hline 23 & $m=0.3203 * I-1.2764$ & $\mathrm{~F}=3.203 * \mathrm{I}-12.764$ & 1 \\
\hline 24 & $\mathrm{~m}=0.314 * \mathrm{I}-1.247$ & $F=3.14 * I-12.47$ & 1 \\
\hline 25 & $\mathrm{~m}=0.3173 * \mathrm{I}-1.2376$ & $\mathrm{~F}=3.173 * \mathrm{I}-12.376$ & 1 \\
\hline
\end{tabular}

(3) Field experiment

Devices were moved to field and soil outline and soil compactness distribution were measured.

Test interval of soil outline was $8 \mathrm{~mm}$, test width was $200 \mathrm{~mm}$; test interval of soil compactness was $4 \mathrm{~mm}$, and test soil depth was $100 \mathrm{~mm}$. Test data were led into matlab and obtained the figures of soil outline and soil compactness distribution (Fig.8 and Fig.9).

Results showed that the device could test soil compactness distribution as well as soil outline on seedbed. It would provide convenient measure tool for research on soil compactness distribution.
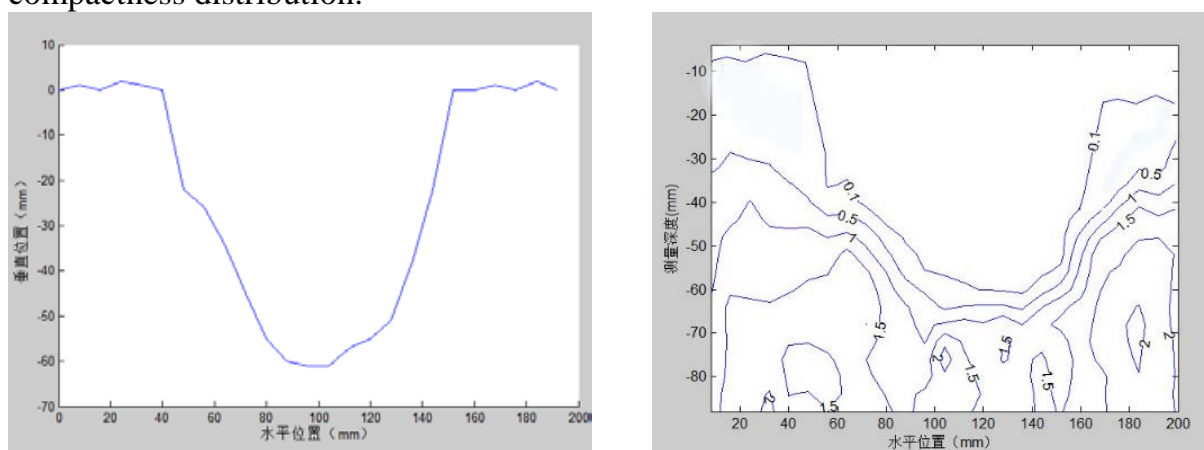

Fig. 8. Soil outline of seedbed

Fig. 9. Distribution of soil compactness distribution

\section{Conclusions}

(1) In order to solve the problems that present test device of soil compaction had only one test pin and couldn't test the soil compaction distribution on seedbed, test device of soil outline and compaction distribution in the filed based on sensors was designed to test soil outline and soil compaction distribution on the seeding bed.

(2) Linear equation between $L$ and $I$ for distance sensor was obtained from calibration results of distance sensor; linear equation between $m$ and $I$ and linear equation between $F$ and $I$ for each pressure sensor were obtained through calibration results of pressure sensors. 
(3) Field experiment showed that the device could test soil compactness distribution as well as soil outline on seedbed. It would provide convenient measure tool for research on soil compactness distribution.

\section{Acknowledgment}

Funds for this research were provided by the National Key Research and Development Plan (2016YFD0200604), Beijing Natural Science Foundation (3174050) the Fundamental Research Funds for the Central Universities (2018QC153), and Recommend international advanced agricultural science and technology plan (2016-X26).

\section{References}

1. Li Duren, Gao Xuke, Wang Deshui: Effects of compaction on soil physical property and crop emergence. Soil Fertility, 05: 5-7 (1981)

2. Yang Xitian, Dong Huiying, Yoshinari Yamadera: On effect of soil hardness on development of seeded and planted seedling root system. Science of Soil and Water Conservation, 3(4): 60-64, 69 (2005)

3. He Mingrong, Wang Zhenlin: Effects of soil compactness on grain yield and quality of wheat. Acta Bot. Boreal. -Occident. Sin., 24(4): 649-654 (2004) 
4. Wu Yongbo, Liu Shuang: Impact of soil compaction on soil property and crop growth. China Forestry Science and Technology, 24(1): 15-17 (2010)

5. Nambiar E K, Sands R.: Effects of compactness and simulated root channels in the subsoil on root development,water uptake and growth of radiata pine. Tree physiology, 397-306 (1992)

6. Tong Jin, Zhang Qingzhu, Li Guo, Chang Yuan, Guo Yingjie, Zhu Fengwu, Chen Donghui, Liu Xin: Compaction performance of biomimetic compaction roller to soil. Journal of Bionic Engineering, 12, 152-159 (2015)

7. G.R.Mari, Ji Changying, Zhou Jun: Effects of soil compactness on soil physical properties and nitrogen, phosphorus, potassium uptake in wheat plants. Transactions of the CSAE, 24(1): 74-79 (2008)

8. Hattori D, Kenzo T, Irino KO, Kendawang JJ, Ninomiya I, Sakurai K: Effects of soil compaction on the growth and mortality of planted dipterocarp seedlings in a logged-over tropical rainforest in Sarawak, Malaysia. For Ecol Manag 310:770-776 (2013)

9. Stanisław G, Maciej T G, Tomasz H, Andrzej R: Changes in root system structure, leaf water potential and gas exchange of maize and triticale seedlings affected by soil compaction. Environmental and Experimental Botany, 88, 2-10 (2013)

10. Shi Yanqin, Chen Yuanquan, Sui Peng, Nie Zijin, Gao Wangsheng: Crop land soil compactness: Its causes, insluences, and improvement. Chinese Journal of Ecology, 29(10): 2057-2064 (2010)

11.Jia, H.L., Wang W.J., Luo X.F., Zheng J.X., Guo M.Z., Zhuang J.: Effects of profiling elastic press roller on seedbed properties and soybean emergence under double row ridge cultivation. Soil \& Tillage Research 162, 34-40 (2016)

12. Sun Yulian: Study on knowledge management of roots as related to soil compaction. Kunming University of Science and Technology (2013)

13. Wan Jin, Huang Yuanqing: Study on laser triangulation method measurement. Journal of Sanming University, 23(4): 361-364 (2006) (in Chinese with English abstract)

14.Zhao Yong, Hu Yongbiao, Jin Yuekang, Li Xirong: Non-destructive detection for soil compactness by laser imaging. Journal of Optoelectronics Laser, 23(5): 950-955 (2012)

15. Hu Qingying, You Zheng, Luo Weiguo: Laser triangulation and its application in geometric measurement. Space Measuring Technology, 16(2): 10-14 (1996)

16. Dao Helongyan, Ge Yang: Surface shape measuring with laser. Foreign Metering, 3: 10-11 (1981)

17. Chang Cheng, Zhang Zhifeng: Study on the erroe in thriangular laser measurement. China Science and Technology Information, 23: 61-62, 64 (2006)

18. Bai Lizhen, Zhu Huibin, Kong Xiangying: Research progress of soil compactness measurement system. Journal of Anhui Agri. Sci., 42(35): 12494-12496, 12521 (2014)

19. Meng Fanjia, Sun Yurui, Wang Congying, Lin Jianhui: Design and experiment on improved cone penetrometer with embedded force sensor. Transactions of the Chinese Society for Agricultural Machinery, 44(1): 80-84 (2013) 